\title{
Initial Development of the Iranian Religious Coping Scale
}

\author{
Abdulaziz Aflakseir, PhD \\ University of Shiraz \\ Peter G. Coleman, PhD \\ University of Southampton
}

\section{Abstract}

This study aimed to develop a religious coping measure for Iranians comparable to Pargament's RCOPE scale. A group of university students $(\mathrm{N}=185)$ completed the research measures. The findings of this study demonstrated that the religious coping scale developed for use with Iranians had five factors comprising religious practice, benevolent reappraisal, negative feelings towards God, passive and active religious coping. The study also showed that the different scales of religious coping had good internal consistency and test-retest reliability and construct validity. The results indicated that Iranian students used positive religious coping methods more frequently than negative strategies. The present research also indicated a significant association between the dimensions of positive religious coping, such as religious practice and psychological well-being. The results suggest that this scale may be useful to the researchers interested in religious coping within Islamic context.

Keywords: religious coping, well-being, scale, validity, reliability, Muslims, Iranians

\section{Introduction}

Religious coping involves the use of cognitive or behavioral strategies that are based on religious beliefs or practices to help manage emotional stress or phys- 
ical discomfort (Koenig, 1994). Religious coping comprises the various ways people use their religion and faith to manage stressful situations. Pargament has been the major researcher in the field of religious coping since the publication of his 1997 book The Psychology of Religion and Coping, and many studies have been conducted on religious coping's impact on well-being. Pargament (1997) describes religion as "the search for significance in ways related to the sacred" (p. 32) and coping as "the search for significance in times of stress" (p. 90). Central to his approach is the diversity of the religion-coping connection: "the many faces of religion in coping" (p. 163).

Pargament (1988) introduced three styles in which people can deal with issues of responsibility and control in religious coping activities: Self-directing, deferring, and collaborative. Each of these differs in the amount of activity and responsibility put forth by the individual. In the self-directing style, it is the individual's responsibility to solve problems and make efforts to accomplish this. According to Pargament (1988), the religious frame of reference is hardly used in this coping method; compared to the other two styles there is a much looser connection with traditional religiousness. In the deferring style, individuals defer the responsibility of problem-solving to God and they wait for solutions to emerge through God's active efforts. In the collaborative style, responsibility for the problem-solving process is held jointly by the individual and God; both are working together to solve problems. Pargament states that the collaborative style is the most common religious coping style. Here, neither the individual nor God plays a passive role in the problem solving process.

Subsequently, Pargament, Koenig, and Perez (1998) identified two patterns of religious coping including positive and negative with potential implications for health. The pattern of positive religious coping methods is an expression of a sense of spirituality, a secure relationship with God, a belief that there is meaning to be found in life, and a sense of spiritual connectedness with others. According to them, several forms of religious coping would be a part of this pattern: benevolent religious reappraisal, collaborative religious coping, seeking spiritual support, spiritual connection, religious purification, seeking help from clergy or members, religious helping, and religious forgiveness. In contrast, they believed that the negative religious coping pattern is an expression of a less secure relationship with God, a tenuous and ominous view of world, and a religious struggle in the search for significance. According to them this pattern would be defined by a very different set of religious coping methods: punitive religious reappraisals, demonic religious reappraisals, reappraisals of God's power, spiritual discontent, self-directing religious coping, and interpersonal religious discontent.

There is a large body of empirical evidence that religious/spiritual methods of coping can affect the psychological, social, and physical adjustment of 
people in crisis (e.g., Koenig, George, \& Titus, 2004; Loewenthal, Cinnirella, Evdoka \& Murphy, 2001; Nairn \& Merluzzi, 2003; Pargament, Magyar-Russell, \& Murray-Swank, 2005). Much of the research on religious coping with adversity is based on Pargament's conceptualization. Pargament, Koenig, and Perez (2000) argued that methods of religious coping do not duplicate those of nonreligious coping and religious coping measures continue to predict significant portions of variance in outcomes to life stressors after removing the effects of nonreligious coping measures.

Most studies on religious coping have been carried out in countries with predominantly Judeo-Christian cultures. Although the followers of the monotheistic religions such as Judaism, Christianity, and Islam share basic beliefs on God, judgement and eternity, nevertheless each one has their own beliefs and practices. However, little information is available about the use of religious/ spiritual coping strategies in non-Judeo-Christian populations, especially Muslims.

\section{Religious Coping in Islamic Context}

There is an emphasis within Islamic literature on religious beliefs and practices being used as resources for dealing with life difficulties. Islamic teachings encourage people to be patient, to perform prayer, and trusting and turning to God in times of need and for guidance. Islamic beliefs also give individuals a meaningful interpretation of difficult events. The Qur'an emphasizes clearly that the difficulties in this world are to test the believer and also asking people to have patience in facing their problems. For example, the Qur'an says: "We try you by means of danger, and hunger, and loss of worldly goods, of lives and of [labor's] fruits, But give glad tidings unto those who are patient in adversity" (2:155). Therefore, according to the religious teachings, the negative events have a purpose and people are required to be patient to achieve spiritual growth. There are many verses of the Qur'an and also other sayings from the Prophet asking Muslims to have patience with difficulties. For example the Qur'an says: "You who have attained to faith! Seek aid in steadfast patience and prayer; for, behold, God is with those who are patient in adversity" (2:153). Various Islamic religious sources, particularly in the Qur'an and traditions, give certain recommendations related to feeling better and coping with difficulties through the remembrance of God. For example, the Qur'an says: "Those who believe, and whose hearts find their rest in the remembrance of God-for, verily, in the remembrance of God [men's] hearts do find their rest" (13:12); and "so remember the Name of your Lord and devote yourself with a complete devotion" 
(73:8). Remembrance (thikr) is everything that reminds people of God and every effort they exert in order to bring God to mind (Chittick, 2001). This remembrance begins on the tongue, enters the mind with concentrated consciousness, settles into a heart softened and cleansed through remembrance of God, and manifests in the myriad small actions a person engages in each day. In the Qur'an Muslims are commanded to remember God by invoking His name - Allah; the essential, simplest prayer of Islam is the utterance of God's name. To achieve a heart at peace, one needs to remember God, for it calls down God's response. For example, the Qur'an says "Remember me, and I will remember you" (2:152). Furthermore, there are many recommendations in the Islamic teachings encouraging believers to use certain religious beliefs and activities for coping with difficult situations. Some of these religious activities involve specific prayers, fasting, pilgrimage, and reciting verses of the Qur'an.

Several studies on religious coping among Muslim populations have been reported (e.g., Husain, 1998; Ghorbani, Watson, \& Khan, 2007; Loewenthal et al., 2001; Khawaja, 2008). Kesselring and colleagues (1986) compared the use of religious coping between Egyptian and Swedish people. They reported that 92\% of Egyptian patients with cancer voiced a belief that God will help them, in contrast to only $37 \%$ of the Swedish patients faced with the same disease. Similarly, Mehta (1997) in a qualitative study on elderly Malay Muslims reported that the elderly attributed their aging process and its accompanying decrements to the Will of God. Some respondents also mentioned reciting verses of Quran to manage the pain of their headaches. Hussain and Cochrane (2003), in a study on Muslim women with depression, found that coping through religion was the most common strategy, where the women prayed for help and many read prayer and verses from the Quran specifically to ask for protection from illness and symptoms. Some of them also simply resumed the obligatory five daily prayers that they had either stopped performing or did not usually read-feeling that if they tried to be better Muslims, the praying would indicate a 'sincere' need for help. Loewenthal and colleagues (2001) in a study of depressed people among Christians, Jews, Muslims, Hindus, followers of other religions and the non-religious, reported that the Muslims believed more strongly than other faith groups in the efficacy of every form of religious activity in coping with depression.

Since Allport (1967) conceptualized his theory on religion and developed the Religious Orientation Scale (ROS-Allport \& Ross, 1967) for measuring religiosity, several questionnaires have been developed to measure religiosity and spirituality (e.g., Boudreaux et al., 1995; Carver et al., 1997). Most studies have used the global religious indicators such as attending places of worship and reading scripture to assess religious coping. However, Pargament and col- 
leagues (1998) argued that the field needs to go beyond global measures of religion and spirituality into the specific ways that religion expresses itself. Subsequently, Pargament developed several scales to address the limitation of existing religious coping measures. Pargament's scale of religious coping has been used in many studies investigating the connection between religious coping and well-being (see Hill \& Pargament, 2003; Koenig, 2003; Nairn \& Merluzzi, 2003). Pargament et al. (1998) developed the Religious Coping scale (RCOPE), a theoretically based measure that assesses the full range of religious coping strategies. The RCOPE can be divided in two parts: positive and negative religious coping.

However it is important to note that some of the religious coping aspects identified by Pargament are in fact contrary to Islamic belief. These include collaborative religious coping, seeking control through a partnership with God and demonic reappraisal. It is essential to develop a scale which is suitable and sensitive to Islamic beliefs and practices.

There have been several studies on developing religiosity measures for Muslims. For example, a religious coping scale has been developed for Pakistanis based on the RCOPE (Khan \& Watson, 2006). Furthermore, Jana-Masri and Priester (2007) developed the Religiosity of Islam Scale (RoIS), a Qur'anbased instrument to assess Islamic religiosity. Moreover, another religious coping scale has been developed for Arab Americans of both Christian and Muslim faiths based on Rasch rating scale analysis (Amer, Hovey, Fox, \& Rezcallah, 2008). Psychological measure of Islamic Religiousness (PMIR) another tool designed to assess Islamic practices and beliefs (Abu Raiya, Pargament, Stein, \& Mahoney, 2008). The current research was conducted in order to develop an appropriate measure to assess religious coping in Iranian Muslims. This research attempts to highlight the use of religious coping within an Iranian context. The development of a new measure of religious coping may facilitate further research that can ultimately improve our understanding of religious coping methods that Muslims use to cope with stressful situations.

\section{Purpose of the study}

The primary aim of this study was to develop a reliable and valid measure of religious coping that assesses a wide range of religious coping strategies used by Muslims. The second purpose of the current study was to determine whether religious coping strategies are associated with the psychological well-being of Iranian university students, as has been found in prior research with other religious traditions. This study also aimed to examine gender differences on different aspects of religious coping. 


\section{Method}

\section{Exploratory study on religious coping}

To understand which types of coping methods Iranians used when faced with stressful situations, 46 undergraduate students studying at Shiraz University participated in this study. There were 18 males and 28 females. The ages ranged between 18 and 22 years $($ mean $=20.26$ ). They were asked to respond to an open-ended question regarding coping in general. The participants were also asked to describe an event in which they experienced stress during the last two years. These events included the death or illness of family members, a romantic breakdown, financial problems, or academic problems. They were asked then to rate the degree of stressfulness of their experience on a 4-point scale from a little negative (1) to extremely negative (4). They were also asked to determine how they had coped with their situation. The item "what did help you to cope with your situation when you experienced stress?" was used to identify which coping strategies they had used to manage their problems.

The descriptive analyses of data on exploratory study indicated that participants reported a moderate level of stress in facing various negative events. In this study, $47.5 \%$ of participant reported that they experienced extremely negative stress, $29.5 \%$ moderately negative, $13.9 \%$ somewhat negative, and $9 \%$ reported slightly negative. The mean score of stressful experience for the sample was 3.14 on a four-point scale. The students also described various ways of coping in answering the above question including both non-religious and religious coping strategies. The term religious coping refers to "the dependence on religious belief or activity to help manage emotional stress or physical discomfort" (Koenig, 1994, p. 161). The term non-religious coping refers to any other strategies to cope with difficulty situations. In responding to this question, $37 \%$ of the participants stated that a religious belief or practice helped them to cope with their difficult situation. The most frequent religious coping strategies mentioned were trust in God, prayer, remembering God, reciting verses of the Qur'an, reading certain prayers and $d u^{\prime} a a$ (supplication), and belief in destiny. For example, one of the students said that "when I face with hard circumstances, I recite some verses of the Qur'an and it makes me feel calm." They also described some non-religious coping strategies such as engaging in other activities, crying, and trying to not think about the problem.

\section{Pilot questionnaire study}

Based on results of the exploratory study and Islamic resources, an initial scale with 30 items was developed. This scale was administered on 25 undergraduate students at Shiraz University to identify potential problems including the 
scale's wording and the appropriateness of items. The purpose of this was to pilot the questionnaire and to ensure comprehensibility of the measure. Specifically, care was taken to avoid items that were exceptionally lengthy, doublebarrelled, or had ambiguous pronoun references. Three items that were not phrased clearly based on respondents' feedback were dropped from the scale. The 27 items that were retained had good face validity, and reflected the purpose of the scale. The sample of pilot study was excluded from the main study.

\section{Main Study}

\section{Participants}

A total of 185 undergraduate students completed the questionnaires. They were recruited from the various Schools of the University of Shiraz including social sciences, psychology, biology, engineering, and theology using random cluster sampling. They were asked to take part in this study and completed the research questionnaires in classes. Students who agreed to participate were asked to read and sign the consent form. The sample comprised $63 \%$ female and $37 \%$ male. Ninety-four percent of the respondents were single. The participants' age ranged from 18 to 25 with a mean ages of $19.9(\mathrm{SD}=1.37)$.

\section{Measures}

Iranian Religious Coping Scale: The religious coping measure included 27 items scored on a five-point scale from 0 (not at all) to 4 (a great deal). To develop this scale, 11 items which appear to be applicable for Muslim were adopted from Pargament's scale (RCOPE items 1, 3, 4, 5, 8, 10, 15, 16, 19, 21, 22). These items were derived from the different subscales of the RCOPE including spiritual discontent, reappraisal of God's power, benevolent reappraisal, and active and passive religious deferral. These items were translated from English to Farsi and then back-translated. Furthermore, since religious practice plays a significant role, eight items relevant to Muslim practices were generated from the Islamic text and interviews with individuals facing stressful experiences. Furthermore, eight other items relevant to Islamic beliefs were generated from the Islamic resources such as the Qur'an and traditions. An attempt was also made to include a wide range of religious beliefs and practices that Muslims use to cope in their daily life. The religious coping methods were defined based on different functions of religion that seem to be important for Muslims. The religious functions include positive and negative patterns of religiosity. Negative patterns of religiosity were included due to previous research finding a positive relationship between dysfunctional forms of religiosity and mental 
health problems. The following aspects were included in this scale: religious practice, religious benevolent reappraisal, negative feelings toward God, and passive and active religious coping strategies.

Spiritual Belief Scale (King, Speck, \& Thomas, 2001): A measure of belief strength taken from the Royal Free Interview for Spiritual and Religious Beliefs was used to assess the convergent validity of the new scale. The scale is composed of five items on a 10-point scale. The authors claim the scale was designed specifically to assess a wide range of spirituality beliefs not specific to any religion. This measure had been validated in a research conducted on an Iranian sample and it was found to have a good reliability and validity with Cronbach alpha of .84 for Iranian people. Factor analysis findings resulted in one factor similar to the original study (Aflakseir, 2007).

General Health Questionnaire (GHQ; Goldberg \& Williams, 1988): The GHQ was designed as a reliable screening instrument for psychological distress. The Farsi 12-item version of the GHQ was used to measure depression and psychiatric morbidity. This scale was found to have good reliability and validity for Iranians (Montazeri et al., 2003). When the psychometric properties of this scale were examined in this research, it had good reliability and validity, with Cronbach alpha of .86 .

\section{Results}

\section{Factor Analysis of Religious Coping Scale}

Factor analysis with principal component analysis was used to extract factors from the correlation matrix. All 27 items were subjected to the factor analysis using principal components extraction and oblique rotation. Only items with loadings equal to or greater than 0.30 were retained for further analysis. The five items with loading lower than 0.30 were dropped and the remaining 22 items were subjected to another factor analysis. This analysis resulted in 5 factors with eigenvalues greater than 1.0. These factors explained $64 \%$ of the variance in scores. The factors with their corresponding items and loadings can be seen in Table 1. Of the 22 items retained, six items loaded on Factor 1, four items loaded on Factor 2, six items loaded on Factor 3, three items loaded on Factor 4, three items loaded on Factor 5. Furthermore, Factor 1 had an eigenvalue of 6.9 , accounting for $31 \%$ of the variance; Factor 2 had an eigenvalue of 2.8, accounting for $12.7 \%$ of variance; Factor 3 had an eigenvalue of 1.8, accounting for $8.3 \%$ of variance; Factor 4 had an eigenvalue of 1.3, accounting for $6.2 \%$ of variance; and Factor 5 had an eigenvalue of 1.2, accounting for $5.3 \%$ of the variance. 
The items that loaded on Factor 1 reflected a focus on religious deeds and practice (e.g., sought comfort and guidance by reading the Qur'an). The second factor highlighted negative feelings toward God (e.g., expressed anger at God for letting a problem happen). The items loading on Factor 3 were related to the benevolent reappraisal (e.g., saw my situation as God's will). The fourth factor reflected the passive way of religious coping (didn't try to do much; just assumed God would handle it). Finally, the items of the fifth factor were relevant to an active way of coping (e.g., turned the situation over to God after doing all that I could). The findings of this study showed clear and separate factors for various dimensions of religious coping strategies. Thus, in subsequent analyses, the Religious Coping Scale was split into five subscales: practice, benevolent reappraisal, negative feeling towards God, passive, and active religious coping.

\section{Intercorrelation between the Subscales of the Measure}

Pearson correlation coefficients were computed to determine the relationship between the six subscales of the Religious Coping Scale. Table 2 shows the intercorrelation between the different scales. As can be seen, the religious practice subscale was positively correlated with benevolent reappraisal and active coping. Furthermore, the practice and benevolent reappraisal religious copings subscales were negatively correlated with negative feelings toward God. Results also showed a negative association between active and passive religious coping subscales. These inter-correlations suggest that, although the dimensions of religious coping are not exclusive, they represent distinct ways of coping by Muslims.

\section{Reliability of Religious Coping Scale}

Internal Consistency: To examine internal consistency of the Religious Coping Scale, Cronbach's alpha scores were computed and found to have a good internal consistency for different subscales. Cronbach's alpha scores for different dimensions of the scale were .89 for religious practice, .79 for benevolent reappraisal, .79 for negative feeling, .72 for passive, and .79 for active religious coping strategies. The Cronbach's alpha for subscales of religious coping seems to be acceptable.

\section{Validity of Religious Coping Scale}

Concurrent Validity: Spiritual Strength Scale (King et al, 2001), a five-item scale was used to assess the concurrent validity of the Religious Coping Scale. This 
TABLE 1. Factor Analysis of Religious Coping Measure

\begin{tabular}{|c|c|c|c|c|c|}
\hline Scale items & 1 & 2 & 3 & 4 & 5 \\
\hline \multicolumn{6}{|l|}{ Factor 1 'Religious Practice’ $(\alpha=.89)$} \\
\hline 11. Sought tranquillity by remembrance of God & .84 & -.12 & .35 & .03 & .15 \\
\hline 2. Sought comfort and guidance by reading the Qur'an & .82 & -.26 & .39 & .12 & .24 \\
\hline 7. Appealed to Prophet and Imams & .82 & -.18 & .29 & -.03 & .20 \\
\hline 14. Read certain prayers & .79 & -.22 & .29 & .00 & .22 \\
\hline 20. Attended pilgrimage when I felt upset & .78 & -.18 & .14 & .03 & .24 \\
\hline 17. Sought help with prayer. & .75 & -.30 & .42 & .13 & .23 \\
\hline \multicolumn{6}{|l|}{ Factor 2 ‘Negative Feelings toward God’ $(\alpha=.79)$} \\
\hline 8. Felt God had forgotten me (Wondered if God really cares)* & -.21 & .83 & -.17 & -.15 & -.19 \\
\hline 12. I was disappointed with God's grace and mercy & -.19 & .78 & -.07 & -.27 & -.28 \\
\hline 21. I expressed anger at God for letting this problem happened* & -.20 & .78 & -.19 & -.13 & -.19 \\
\hline 3. Realized that God cannot answer all of my prayers* & -.08 & .65 & .05 & -.20 & -.08 \\
\hline \multicolumn{6}{|l|}{ Factor 3 'Benevolent Reappraisal’ $(\alpha=.79)$} \\
\hline 13. Viewed my situation as a trial from God & .26 & -.26 & .74 & -.18 & .26 \\
\hline 1. Saw my situation as God’s will* & .06 & -.09 & .73 & -.29 & .31 \\
\hline 18. My suffering was purification of my sins & .59 & -.11 & .71 & .12 & .06 \\
\hline 6. Sought patience because God is with those who patiently persevere & .57 & -.12 & .68 & .06 & .05 \\
\hline 22. Suffering and difficulties strengthened my faith* & .21 & .00 & .63 & -.03 & .39 \\
\hline 16. Thought suffering may bring me closer to God* & .54 & -.19 & .62 & .24 & .10 \\
\hline \multicolumn{6}{|l|}{ Factor 4 ‘Passive’ $(a=.72)$} \\
\hline 19. Didn't try to do much; just assumed God would handle it* & .07 & .20 & .13 & -.79 & -.15 \\
\hline 9. Was destined to have this situation, so I didn't try to change it & -.11 & .13 & .16 & -.74 & .20 \\
\hline 4. Didn't do much, just expected God to solve my problems for me* & .04 & .35 & -.05 & -.73 & -.31 \\
\hline \multicolumn{6}{|l|}{ Factor 5 ‘Active’ $(\alpha=.79)$} \\
\hline 10. Turned the situation over to God after doing all that I could* & .32 & -.27 & .28 & .11 & .80 \\
\hline 15. Did what I could and turned the rest over to God* & .44 & -.25 & .36 & .17 & .78 \\
\hline 5. Did everything I could, then I asked God to sort out it Himself* & .46 & -.51 & .26 & .03 & .62 \\
\hline Eigen Value & 6.8 & 2.7 & 1.8 & 1.3 & 1.2 \\
\hline$\%$ of Variance Explained & $31 \%$ & $12 \%$ & $8 \%$ & $6 \%$ & $5 \%$ \\
\hline
\end{tabular}

Note: $n=185$

*RCOPE.

TABLE 2. Intercorrelations between the scales of the Religious Coping

\begin{tabular}{lccccc}
\hline Subscale & 1 & 2 & 3 & 4 & 5 \\
\hline 1. Religious Practice Coping & 1 & & & & \\
2. Religious Reappraisal & $.57^{\star \star}$ & 1 & & & \\
3. Negative Feelings toward God & $-.26^{\star \star}$ & $-.19^{\star \star}$ & 1 & & \\
4. Passive Religious Coping & .02 & .06 & $.28^{\star \star}$ & & \\
5. Active Religious Coping & $.46^{\star \star}$ & $.42^{\star \star}$ & $-.32^{\star \star}$ & $-.21^{\star \star}$ & 1 \\
\hline
\end{tabular}

${ }^{* *} p<.01 ;{ }^{*} p<.05$ 
scale was designed to measure spiritual coping in patients admitted to the hospital with an acute physical illness. The scale was found to have a very good reliability and validity in a previous study of Iranians (Aflakseir, 2007). The results showed a high correlation between this scale and the scales of practice $(\mathrm{r}=.74, \mathrm{p}<.01)$, benevolent reappraisals $(\mathrm{r}=.58, \mathrm{p}<.01)$, negative feelings toward God $(\mathrm{r}=-.65, \mathrm{p}<.01)$ and active $(\mathrm{r}=.52, \mathrm{p}<.01)$ religious coping. The results did not show any association between the spiritual scale and the passive religious coping dimension $(\mathrm{r}=.06, \mathrm{p}<.72)$.

Known group approach: To evaluate the construct validity of the scale, the known group approach was used. For this purpose, 30 theology students were asked to complete the religious coping scale and then their scores were compared with non-theology students. It was hypothesized that theology students use religious coping strategies more frequently than those studying other subjects. Independent samples t-tests were computed on each of the dimensions of the Religious Coping Scale. The two groups were significantly different on three dimensions of the scale. The theology students had a higher score on most dimensions of religious coping compared with the rest of the respondents. Results indicated a significant difference on practice, benevolent reappraisal, and negative feelings toward God. However, there was no significant difference on passive and active religious coping strategies. The results are presented in Table 3.

\section{Descriptive Findings}

Religious Coping: Descriptive statistics for different scales of religious coping measure are shown in Table 4. In general, positive patterns of religious coping were used more frequently than the negative patterns by Iranian students. The most commonly used religious coping strategies were active, practice, and benevolent reappraisal religious coping methods, while the least commonly used was passive religious coping.

TABLE 3. Comparing the Means of the Different Scales of Religious Coping Scale for Theology Students and Non-Theology Students

\begin{tabular}{|c|c|c|c|c|c|}
\hline \multirow[b]{2}{*}{ Subscale } & \multicolumn{2}{|c|}{ Theology Students $(n=30)$} & \multicolumn{3}{|c|}{ Non-Theology Students $(n=155)$} \\
\hline & Mean & SD & Mean & SD & $\mathrm{t}$ \\
\hline Practice & 3.05 & 0.73 & 2.56 & 1.03 & $2.50 * \star$ \\
\hline Benevolent & 2.75 & 0.55 & 2.37 & 0.75 & $2.59 * \star$ \\
\hline $\begin{array}{l}\text { Negative Feelings } \\
\text { Toward God }\end{array}$ & .62 & 0.48 & 1.06 & 0.88 & $-2.65^{\star \star}$ \\
\hline Passive & 1.01 & 0.49 & .86 & 0.76 & 1.04 \\
\hline Active & 3.11 & 0.92 & 2.89 & 0.84 & 1.11 \\
\hline
\end{tabular}

Note: ${ }^{\star \star} p<.01 ;{ }^{*} p<.05$ 
TABLE 4. Means \& Standard Deviations of Participants on Scales of the Religious Coping Measure

\begin{tabular}{lccc}
\hline Subscales & $N$ of Items & Mean & SD \\
\hline Practice & 6 & 2.63 & 1.25 \\
Benevolent & 6 & 2.43 & 1.05 \\
Negative Feelings & 4 & 1.00 & 1.10 \\
Passive & 3 & .78 & .56 \\
Active & 3 & 2.92 & .94 \\
\hline
\end{tabular}

Relationships between the subscales of Religious Coping measure and psychological well-being outcome

To examine the relationship between different dimensions of religious coping and psychological well-being, Pearson's correlations were used. Results from this analysis showed that practice and active religious coping scales had a modest but significant negative correlation with the GHQ measure $(r=-.21, \mathrm{p}<$ $.001 ; \mathrm{r}=-.21, \mathrm{p}<.001$ ), while the negative feelings toward God dimension had a significant positive correlation with the GHQ measure $(\mathrm{r}=.19, \mathrm{p}<.001)$. No significant correlation was found for passive and benevolent reappraisal religious coping in relation to psychological well-being measured by the GHQ. The results of this study indicated that individuals who used positive religious coping strategies scored low on the GHQ measure.

\section{Gender differences on the scales of Religious Coping measure}

Findings of this study also showed that there were several significant gender differences in the reported use of various religious coping strategies. Results from the independent sample t-test indicated that there was a significant main difference between men and women in 'practice' $(\mathrm{t}=-2.11, \mathrm{p}<.05)$ and 'benevolent reappraisal' $(\mathrm{t}=-2.00, \mathrm{p}<.05)$ religious coping methods. In the present research, women had higher scores on practice and benevolent religious coping. In other words, women used benevolent reappraisal and practice religious coping more frequently than men. The results found no significant differences between men and women on negative feeling, and passive and active religious coping.

\section{Discussion}

The main purpose of this study was to develop a reliable and valid measure of religious coping for Iranians and also to investigate the association between use of religious coping and psychological well-being. 


\section{Psychometric properties of the Religious Coping scale}

Factor analyses of the religious coping strategies used by Iranian students revealed six factors. Factor structure of scale was largely as hypothesized and was largely consistent with the conceptualization and construction of the subscales. The practice religious coping had a large contribution in common variance $(20 \%)$. These results indicate that religious practices have a significant role in the coping of Muslims in stressful conditions, as Islamic teachings encourage Muslims to practice their religion. Furthermore, the items of the scale account for large common variances (64\%) which indicate respondents used a wide range of religious coping strategies. Reliability of different scales of religious coping, assessed by Cronbach's alpha coefficient, appeared satisfactory, with all Cronbach's alpha being in the 0.69 to 0.89 range, indicating that the items of subscales are homogenous. In addition, the moderate correlation between this scale and Spirituality Scale indicated an acceptable convergent validity of the religious coping measure.

The findings of this study regarding the significant differences between Theology students and non-Theology students on 'practice' ( $m e a n=3.05$ vs. 2.56 ), 'benevolent reappraisals' (mean $=2.75$ vs. 2.37 ), and 'negative feelings' (mean $=.62$ vs. 1.62$)$ religious coping methods lend support to the construct validity of scale. The findings of the current study, indicating more frequent use of religious coping methods by the Theology students compared to other students, are in line with other studies (see Pargament, Koenig, Tarakeshwar, \& Hahn, 2001).

Moderate intercorrelations among the religious coping scales suggest that methods of religious coping are applied in combinations and patterns. Rather than measure the variety of religious coping methods in detail, it is possible to assess a broad range of religious coping activities. Furthermore, these intercorrelations suggest that people did not make use of religious coping strategies individually. But they applied them in some combination with each other. A negative correlation between passive and active religious coping show that these two styles of religious coping measure two different methods of coping and are also consistent with Pargament's study (1988) and other studies (e.g., Pieper \& van Uden, 2005).

Although the correlation between passive and active religious coping measures was significant, the effect size is not even at a moderate level. Although Pargament and Pieper reported a modest negative correlation between the two styles of coping $(r=-0.43)$, the moderate negative correlation between passive and active religious coping $(\mathrm{r}=-.20, \mathrm{p}<.01)$ in this study may indicate that some Iranian students passively waited for God to change their situation and mostly they relied on the destiny. 


\section{Use of religious coping among Iranian students}

The results of the current study indicated that religious coping was a salient construct for Iranians. The participants in the qualitative pilot study and also in the questionnaire study reported using diverse religious coping strategies in the face of stressful situations. These findings are in agreement with other studies within the Muslim context (see Amer et al., 2008; Jana-Masri \& Priester, 2007; Loewenthal et al., 2001). They indicated relatively infrequent use of negative feeling towards God (e.g., expression of anger at God) when compared to positive religious coping methods (e.g., active religious surrender). The sample in this study scored higher in items of positive religious coping strategies and lower in the items of negative feeling compared to other religious sample studies carried out in the U.S. (see Pargament et al., 1998; Tarakeshwar, Pargament, \& Mahoney, 2003). For example, participants' means on practice, benevolent reappraisal and active religious coping were $2.80,2.42$, and 2.18 respectively; while the sample taken by Pargament and colleagues scored lower on similar scales ( $M=1.52$ (benevolent reappraisal); $M=1.03$ (active religious coping), (Pargament et al., 2000).

Higher scores of participants on practice religious coping reflect the importance of religious activities for Muslim people. The participants also scored higher on the benevolent reappraisal religious coping sub-scale compared with passive and negative feelings toward God. It appears that Islamic teachings help people to redefine negative events, accept their situation and interpret it in a more positive framework. There are many verses of the Qur'an indicating that difficulties are a trial from God to test the believers. These findings suggest that individuals who use positive religious coping may adopt a positive view of stress, interpreting stressful events as opportunities for personal development and growth.

This study also showed that participants used passive religious coping methods more frequently compared with Pargament and colleagues' (2000) study ( $\mathrm{M}=.48, \mathrm{SD}=.58$ on a four- point scale) and other more recent studies (e.g., Alma, Pieper, \& van Uden, 2003). The participants in this study did not have control over the stressful situations in most cases, such as death or illness of family member, and therefore, the results of this research on the use of passive and active religious coping strategies should be interpreted with caution.

Association between different patterns of religious coping and psychological well-being

Findings of the current research showed that there was a negative significant association between positive religious coping strategies and GHQ and also a 
positive significant association between negative feelings toward God with the GHQ. Indeed, those who used positive religious coping had a lower level of distress, while participants with negative feelings toward God had a higher level of distress. The findings of this study are consistent with previous research indicating a positive relation between well-being and positive religious coping methods (see Pargament et al., 1998). This study also showed no correlation between passive religious coping and well-being (see Table $10 ; \mathrm{r}=.07$ ), while Pargament and colleagues reported a negative association between passive religious deferral and some well-being indexes such as self-control. The participants in the current study had no control on their situation in most cases; therefore, the passive and active religious coping strategies may not be applicable to them. On the other hand, the findings of this research indicating no correlation between passive religious coping method and psychological wellbeing are consistent with a study conducted by Alma and colleagues (2003) in the Netherlands. They also did not find any associations between passive religious coping and anxiety.

Gender differences in religious coping methods

The findings of the current study showed a significant difference on some religious coping methods between men and women. Women scored higher than men on dimensions of practice, benevolent reappraisal, and active religious coping methods. These findings support literature showing that women use religious coping strategies more frequently than men and the results are consistent with the general view that women are more religious than men (BeitHallahmi \& Argyle, 1997; Francis \& Wilcox, 1996). Findings also support Pargament's (1997) explanation that women have less societal access to resources and power. Therefore, religion becomes an accessible resource that is easily called upon for coping in times of crisis.

\section{Limitations and implications}

There are several limitations in the current study which need to be considered. The current research was carried out on undergraduate Iranian students, mainly females $(65 \%)$, with ages ranging from 18 to 25 years. Therefore, this sample was not representative of the wider Iranian population. Future studies need to be conducted on larger samples, involving different age groups and gender balance. Furthermore, more research needs to be done on the relationships between different styles of Islamic religious beliefs and practice and various dimensions of psychological well-being. 


\section{Conclusions}

The findings of this study demonstrated that the religious coping scale developed for use with Iranians had five factors including practice, benevolent reappraisal, negative feelings toward God, and passive and active religious coping. The findings also indicated that the different subscales of religious coping had good internal consistency. Furthermore, the research showed that the scale had good validity. The results showed that Iranian students used positive religious coping methods more frequently than a negative religious coping strategy. The present research also indicated a moderate association between religious coping indexes and psychological well-being. The present findings provide insight into the different ways of religious beliefs and practice that Iranian Muslims use to cope with difficult situations.

\section{References}

Aflakseir, A. (2007). Role of religious coping and personal meaning in the mental health of Iranian disabled war veterans. Unpublished $\mathrm{PhD}$ Thesis, University of Southampton, United Kingdom.

Abu Raiya, H., Pargament, K. I., Stein, C., \& Mahoney, A. (2007). Lessons learned and challenges faced in developing the psychological measure of Islamic religiousness. Journal of Muslim Mental Health, 2, 133-154.

Allport, G. W., \& Ross, J. M. (1967). Personal religious orientation and prejudice. Journal of Personality and Social Psychology, 5, 432-443.

Alma, H. A., Pieper, J. Z. T. \& van Uden, M. H. F. (2003). When I find myself in times of trouble: Pargament's religious coping scales in the Netherlands. Archives for the Psychology of Religion, 24, 64-74.

Amer, M., Hovey, J, D., Fox, C. M., \& Rezcallah, A. (2008). Initial development of the brief Arab religious coping scale (BARCS). Journal of Muslim Mental Health, 3, 69-88.

Beit-Hallahmi, B., \& Argyle, M. (1997). The psychology of religious belief, behaviour and experience. London: Routledge.

Boudreaux, E., Catz, S., Ryan, L., Amaral-Melendez, M., \& Brantley, P. J. (1995). The ways of religious coping scale: reliability, validity, and scale development. Assessment, 2, 233-244.

Carver, C. S. (1997). You want to measure coping but your protocol's too long: Consider the brief COPE. International Journal of Behavioral Medicine, 4, 91-100.

Chittick, W. C. (2001). Sufism: A short introduction. Oxford: Oneworld Publications.

Francis, L. J., \& Wilcox, C. (1996). Religion and gender orientation. Personality and Individual Differences, 20, 119-121.

Ghorbani, N., Watson, P. J., \& Khan, Z. H. (2007). Theoretical, empirical, and potential ideological dimensions of using western conceptualizations to measure Muslim religious commitments. Journal of Muslim Mental Health, 2, 113-131.

Goldberg, D. P., \& Williams, P. (1988). A user's guide to the General Health Questionnaire. Windsor: NFER-Nelson. 
Hill, P. C., \& Pargament, K. I. (2003). Advances in the conceptualization and measurement of religion and spirituality: Implications for physical and mental health research. American Psychologist, 58, 64-74.

Husain, S. A. (1998). Religion and mental health from the Muslim perspective, in H. G. Koenig (Ed.), Handbook of religion and mental health. New York: Academic Press.

Hussain, F. A., \& Cochrane, R. (2003). Living with depression: Coping strategies used by South Asian women living in the UK suffering from depression. Mental Health, Religion \& Culture, 6, 21-44.

Jana-Masri, A., \& Priester, P. E. (2007). The development and validation of a Qur'anbased instrument to assess Islamic religiosity: The Religiosity of Islam Scale. Journal of Muslim Mental Health, 2, 177-188.

Khan, Z. H., \& Watson, P. J. (2006). Construction of the Pakistani Religious Coping Practices Scale: correlations with religious coping, religious orientation, and reactions to stress among Muslim university students. International Journal for the Psychology of Religion, 16, 101-112.

Khawaja, N. G. (2008). An investigation of the factor structure and psychometric properties of the COPE scale with a Muslim migrant population in Australia. Journal of Muslim Mental Health, 3, 177-191.

King, M., Speck, P., \& Thomas, A. (2001). The Royal Free interview for spiritual and religious beliefs: Development and validation of a self-report version. Psychological Medicine, 31, 1015-1023.

Koenig, H. G. (1994). Aging and God: Spiritual pathways to mental health in midlife and later years. New York: Haworth Pastoral Press.

Koenig, $\uparrow$ H. G. (2003) "Religion, spirituality and health: An American physician's response." Medical Journal of Australia, 178, 51-52.

Koenig, H. G., George, L. K., \& Titus, P. (2004). Religion, spirituality, and health in medically ill hospitalized older patients. Journal of the American Geriatrics society, 52, 554-562.

Loewenthal, K. M., Cinnirella, M., Evdoka, G., \& Murphy, P. (2001). Faith conquers all? Beliefs about the role of religious factors in coping with depression among different cultural religious groups in the UK. British Journal of Medical Psychology, 74, 293-303.

Mehta, K. K. (1997). The impact of religious beliefs and practices on aging: A crosscultural comparison. Journal of Aging Studies, 11, 101-114.

Montazeri, A., Harirchi, A. M., Shariati, M., Garmaroudi, G., Ebadi, M., \& Fateh, A. (2003). The 12-item General Health Questionnaire (GHQ-12): Translation and validation study of the Iranian version. Health and Quality of Life Outcomes, Reproductive BioMedicine Online, 1. Retrieved from http://www.hqlo.com/content/1/1/66.

Nairn, R. C., \& Merluzzi, T. V. (2003). The role of religious coping in adjustment to cancer. Psycho-oncology, 12, 428-441.

Pargament, K. I. (1997). The psychology of religion and coping. New York: Guilford Press.

Pargament, K. I., Kennell, J., Hathaway, W., Grevengoed, N., Newman, J., \& Jones, W. (1988). Religion and the problem-solving process: Three styles of coping. Journal for the Scientific Study of Religion, 27, 90-104.

Pargament, K. I., Koenig, H. G., \& Perez, L. M. (2000). The many methods of religious coping: Development and initial validation of the RCOPE. Journal of Clinical Psychology, 56, 519-543. 
Pargament, K. I., Koenig, H. G., Tarakeshwar, N., \& Hahn, J. (2001). Religious struggle as a predictor of mortality among medically ill elderly patients. A 2-year longitudinal study Archives of Internal Medicine, 161, 1881-1885.

Pargament, K. I., Magyar-Russell, G. M., \& Murray-Swank, N. A. (2005). The sacred and the search for significance: Religion as a unique process. Journal of Social Issues, 61, 665- 687.

Pargament, K. I., Smith, B. W., Koenig, H. G., \& Perez, L. (1998). Patterns of positive and negative religious coping with major life stressors. Journal for the Scientific Study of Religion, 37, 710-724.

Pieper, J., \& van Uden, M. (2005). Religion and coping in mental health care. Amsterdam: Rodopi.

Tarakeshwar, N., Pargament, K. I., \& Mahoney, A. (2003). Initial development of a measure of religious coping among Hindus. Journal of Community Psychology, 31, 607-628. 